\title{
A Meta-Ethnography of Paid Dementia Care Workers' Perspectives on Their Jobs
}

\author{
Cheryl Cook, B.A., Sherri Fay, M.A., and Kenneth Rockwood, MD, FRCPC, FRCP \\ Department of Medicine, Division of Geriatric Medicine, Dalhousie University/Capital District Health Authority, Halifax, NS
}

DOI:http://dx.doi.org/10.5770/cgj.15.37

\begin{abstract}
\section{Background}

While much work has been to evaluate paid workers' perspectives on the care they provide dementia patients, there is no evidence of any systematic review of this topic.
\end{abstract}

\section{Methods}

We conducted a meta-ethnography of the topic "paid dementia care workers' perspectives on their jobs." Multiple databases were searched for qualitative work that reported on workers' opinions and perspectives on their jobs in dementia care, including all settings and types of jobs. A final group of 34 articles were included, and their themes and constructs synthesized using a meta-ethnographic approach developed by Noblit and Hare.

\section{Results}

Five overarching themes uncovered: approach to care, education and training, emotional impact of the work, organizational factors, and relationships on the job. We also describe how the themes are related to each other.

\section{Conclusions}

Interplay of the theme areas shows the importance of dementia-specific education and training in terms of the approach to care and emotional impact of the work. Closing the gap between policy and practice is critical, but achieving this will require that attention be paid to dementia-specific education for all workers, including care leaders.

Key words: dementia, qualitative, perspectives, dementia care

\section{INTRODUCTION}

By 2031, approximately 750,000 Canadians will suffer from Alzheimer's disease or some other dementia. ${ }^{(1)}$ As about
$50-80 \%$ of people in long-term care now have dementia of some type, ${ }^{(2,3)}$ we must address the expectations and strains on these institutions, and especially the workers, to provide dementia care. While much work has been done on workers' perspectives and attitudes of the care they provide persons with dementia $(\mathrm{PwD})^{(4-7)}$ and meta-ethogrpahy is not an unknown methodology in dementia care research, ${ }^{(8,9)}$ there is no evidence of any synthesis of this type on this topic. The recent release of the UK National Dementia Strategy ${ }^{(10)}$ calls to attention the need here in Canada for a systematic approach to dementia care. Foremost in that need is an understanding of the care currently being provided, and the challenges to this, from the perspective of those providing it. Here we report a meta-ethnography on the perspectives of paid dementia care providers on the jobs they do, present the overarching themes uncovered, and discuss the implications of these findings for dementia care.

\section{METHODS}

Three tasks were undertaken: the search, the quality review, and the synthesis. We focused on qualitative papers that offered the unique perspective of paid dementia care workers. Meta-ethnography, as described by Noblit and Hare, ${ }^{(11)}$ was used to synthesize our findings. Meta-ethnography is a well-accepted method for qualitative analyses of multiple studies. ${ }^{(12-17)}$ It offers a systematic approach to uncovering overarching themes across studies, using seven phases (see Figure 1). ${ }^{(11)}$ Meta-ethnography, unlike meta-analysis, focuses on synthesizing interpretations across studies rather than aggregating data across studies.

\section{Integrated Knowledge Translation}

An Integrated Knowledge Translation (IKT) approach (including representatives from research, provincial policy, frontline workers and administrators, and dementia care educators in each step of the work) ${ }^{(18)}$ was used to ensure not only relevance of the topic, but also to assist the research team during the course of the project. For example, the first two phases of a meta-ethnography (getting started and relevancy of the topic) were covered in collaboration with the knowledge users, 
The Seven Phases of the Meta-ethnographic approach

Phase one: getting started

Phase two: deciding what is relevant to the initial interest

Phase three: reading the studies

Phase four: determining how the studies are related

Phase five:translating the studies into one another

Phase six: synthesizing the translation

Phase seven: expressing the synthesis

(Noblit and Hare, 1988, pp.26-29)

FIGURE 1. Seven phases of meta-ethnography

and feedback was received from them at various stages of the project via meetings and electronic document sharing, which informed everything from the search design to the themes uncovered by the review.

\section{Searching and Selecting Publications}

A systematic search was conducted on six databases (PubMed, CINAHL, EMBASE, PsycInfo, ISI: Web of Knowledge, and SocInfo). A full list of search terms is available in Appendix A). Grey literature was also searched through a variety of sources including the Canadian Institute for Health Information, Health Canada, and Google Scholar.

Inclusion criteria: The criteria required that a study's objectives include the perspectives of paid dementia carers, and its methods be qualitative. Studies using a mixed methods design were accepted, but only the qualitative analyses were used for this review. (See Figure 2 for flowchart showing inclusion procedures.) Only papers written in English were considered, due to limits on resources. We chose not to restrict the work by setting, as our interest lay in seeing the full scope of current work. A title and abstract screen was performed on each paper by the research assistant. At any stage, if the exclusion of a paper was in doubt, it was left in and sent to the next stage. For both the abstract and full paper screen, $10 \%$ of the papers were also reviewed by the first and second authors, CC and SF, to validate inclusion. Disagreements were discussed until consensus was reached.

\section{Quality Review}

As there exists no one accepted checklist for quality assessment in qualitative work, a list of questions based on shared elements from a framework created for the UK government, ${ }^{(19,20)}$ and questions about quality of qualitative work posed by Mays and Pope ${ }^{(20)}$ were used:

- Was a methodology stated?

- Is the research question(s) clear?

- Is the study design defensible?

- Is the sampling method well described?

- Are the data collection methods transparent and systematic?

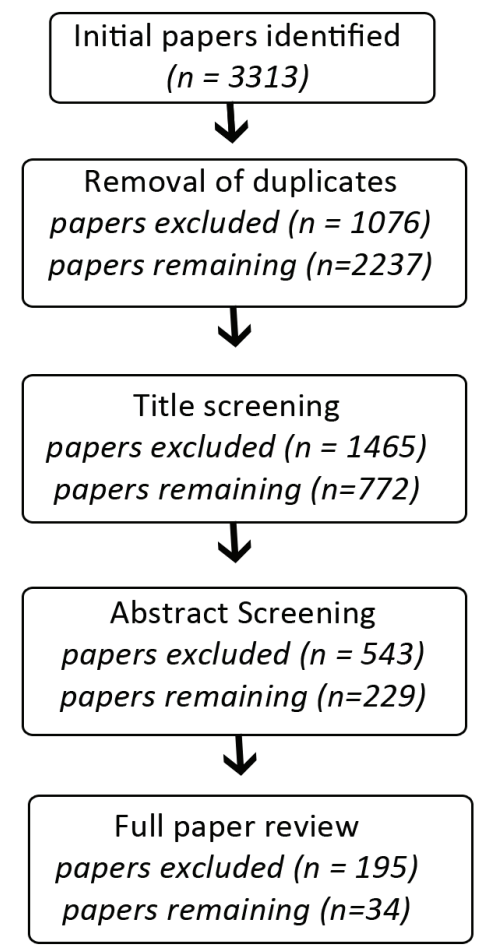

FIGURE 2. Inclusion flowchart

- Are the data analysis methods transparent and systematic?

- Was the analysis appropriate to the methodology?

- Were the findings relevant to the research question?

- Was credibility considered?

- Was transferability considered?

- Was reflexivity considered?

The response to each question could be "yes," "no," or "unclear." The included studies were assessed by CC and SF to validate the choices made. This review was not used to exclude papers from the synthesis, but rather to assist us in better interpreting our findings.

\section{Synthesis}

\section{Reading the Studies}

The selected publications were scanned, entered, and coded using Atlas.ti software. ${ }^{(21)}$ The coding scheme was created inductively to capture various emerging themes and constructs to be indexed and searched.

\section{Determining How the Studies Were Related}

As our interest was in the subjective realities of the workers' experience, and because there were overlapping themes, a reciprocal approach was employed. ${ }^{(11,22)}$ First-level constructs were noted (the perceptions of the participants in the papers). Second-level constructs (themes as reported by the papers' authors) were then collected, using direct quotes from the authors as often as possible, and placed in 
a spreadsheet where their key constructs and themes were noted. These categories of themes were revised by consensus as work progressed.

\section{Translating Studies Into One Another}

Third-level constructs were uncovered by comparing secondlevel constructs across papers, looking for similarities or differences in their descriptions and underlying meanings.

\section{Synthesizing the Data}

The resulting grid had second-level constructs juxtaposed against third-level constructs. The third-level constructs were the themes that emerged from the second level. These emerging themes were categorized by $\mathrm{CC}$, reviewed by SF, and an initial presentation of these was also offered to a group of Knowledge Users representing a variety of backgrounds including research, frontline care, and long-term care management. Through these processes, the final five overarching themes were decided upon.

\section{RESULTS}

\section{Characteristics of Studies Included (see Appendix B)}

\section{Included Studies}

Thirty four studies, published between 1990 and 2010, were included. The work had been conducted in Australia (4), Canada (6), Israel (1), Sweden (12), Taiwan (2), the United Kingdom (4), and the United States of America (5). Additionally, one study's work was conducted in three locations: Australia, Sweden, and the United Kingdom. Twenty-eight of the publications were from peer reviewed journals, one was from a professional publication, and five were theses/dissertations.

\section{Participants}

Participants (in some cases multiple types) included registered nurses (24/34) and frontline (non-nurse) workers such as personal care or continuing care workers $(22 / 34)$, allied health-care workers such as recreation therapists $(8 / 34)$, licensed practical nurses (7/34), physicians (6/34), nurse trainees $(3 / 34)$, and institutional management such as longterm care administrators $(2 / 34)$.

\section{Settings}

Settings (in some cases multiple settings) included residential care (18/34), community care (6/34), acute care (6/34), psychiatric unit (3/34), collective living (3/34), adult day centres $(2 / 34)$, palliative care $(1 / 34)$, and family practice $(1 / 34)$.

\section{Stated Methodology}

Methodologies included phenomenology (12/34), grounded theory (2/34), ethnography (2/34), and action research (1/34), with the rest (17/34) describing a more general qualitative or descriptive methodology.

\section{Description of Themes}

Five overarching theme areas were discovered.

\section{Approach to care}

Descriptions of this ranged from a stated philosophy of care to a more informal discussion of the practical approach to care. A common topic across settings and participant groups was the value of a patient-as-a-person approach to care (described as encouraging individual relationships with patients, with a less task-oriented approach), and the challenges associated with delivering this. Long-term care staff discussed how this approach affected job satisfaction positively ${ }^{(6,23)}$ and allowed workers to offer what they perceived as good quality care..$^{(24,25)}$ In both the acute and long-term care, the relationship with the patient's family was seen as important to fulfilling a "patient-as-a-person" approach to care, with the family being key sources of information about the PwD's pre-disease state. ${ }^{(26,27)}$

The acute care setting was seen as particularly challenging to this approach, often engendering a poor attitude to dementia patients and the work itself. ${ }^{(27,28,29)}$ In communities in Canada's far north, acute and emergency skills were described as more valued than long-term care skills when hiring nurses: “... RNs working in the north did not have 'a good picture of long-term care' and reported that most northern nurses did not have 'any recent training' in dementia and did not want 'anything to do with it'."'(30)

Organizational factors such as staffing cutbacks or poor teamwork and leadership often impacted the practical application of "patient-as-a-person" philosophy of care. ${ }^{(26,31)}$

Dementia-specific education was described as helping long-term care and psychiatric unit workers to contextualize the symptoms of the disease, letting staff see the patient as they were pre-disease. This helped staff cope with challenging symptoms and offer appropriate care. ${ }^{(32-34)}$ Staff who could not contextualize symptoms were felt more likely to experience a negative emotional impact from the work ${ }^{(35)}$ or to respond inappropriately. "The data from RNs and LPNs supported the view that the professional staff was better prepared to respond to these frustrations in caregiving, most probably due to their level of nursing education."(34)

In one acute setting, nursing staff reported little opportunity for dementia education, and typically offered care that followed ward routine, rarely challenging current practice. (29) Primary care physicians reported a change in approach from care to comfort as the disease progressed, and in a change to use of carers as informants, rather than relying on the patients themselves. ${ }^{(36)}$

\section{Education/training}

Dementia-specific education and training were commonly cited across settings, overlapping with many other theme areas. Adequate training and education of staff were cited as contributing to higher job satisfaction. ${ }^{(6,23,37)}$ Likewise, lack of education/training was described as negatively impacting 
care and staff. ${ }^{(26,30,38-40)}$ Lack of education/training was linked to negative feelings such as nihilism, frustration, and irritation, with staff feeling unequipped to deal with the emotional impact of the behaviors and loss that they observed. ${ }^{(41-43)}$ Insufficient or inconsistent training impacted staff's ability to deal with challenging behaviours, or to even understand what that term meant, ${ }^{(4)}$ with some describing staff with less training as more likely to respond inappropriately. ${ }^{(25,34)}$ Education was credited with allowing staff to depersonalize challenging behaviours and respond more appropriately when

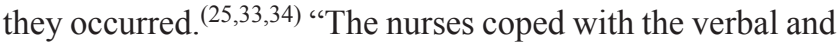
physical aggression by depersonalizing the behavior. They had a thorough understanding of the nature of the disease process associated with dementia and thus were able to realize that the behavior was a result of the disease, rather than a personal attack against them." ${ }^{(43)}$ Lack of knowledge about dementia also meant that some staff treated the inevitable "organic decline" of late-stage patients as a behavioral problem. ${ }^{(45)}$ In the acute care environment, a need for specialized dementia training was indicated, with some staff described as unsympathetic, referring to dementia patients pejoratively, or doing things that caused them distress, which also frustrated some staff members who witnessed this. ${ }^{(28,29)}$

High turnover rates in some facilities also posed an ongoing challenge for staff in terms of orientation and training. ${ }^{(46)}$

\section{Emotional impact of the work}

Many texts dealt with the emotional impact that dementia care has on the workers both negatively and positively, and specifically in terms of job (dis)satisfaction.

Positive: Frontline (non-nursing) staff in one study described wisdom and experience being used to overcome fears or anxieties about giving adequate care and dealing with late stage patients. ${ }^{(24)}$ Nurses in a psychiatric unit described how understanding Alzheimer's allows them to feel more calm and confident in their work. "If their understanding of loss of memory is very comprehensive then I think they (nursing staff) do enjoy it (the care)."(35)

Positive job satisfaction was linked to good relationships with co-workers, feeling respected by management, adequate training and staffing, and the feeling that the work makes a difference to the patients and families. ${ }^{(23,47-49,50)}$

Negative: Staff across care settings and professions described anxiety, uncertainty, frustration, and disappointment in having to do things such as medicate people against their will, and recognized a dilemma between doing no harm and keeping patients alive. ${ }^{(32,42,44,51,52,53)}$ Some described disillusionment and despair in being unable to provide good care due to a lack of training/skills or issues such as understaffing. ${ }^{(26,44)}$ One group of nurses described feeling devalued by other nurses who viewed the work of dementia care as unskilled and unexciting. ${ }^{(33)}$ A group of nurse assistants reported that the administration in their facility made them feel like an extra cost, in contrast with their co-workers by whom they felt valued. ${ }^{(49)}$
The frustrations of dealing with challenging behaviours were also described: getting angry, wanting to quit, treating patients poorly, and feeling abused and humiliated by aggressive behaviours. ${ }^{(34,49)} \mathrm{A}$ lack of education and training impacted nurses and nurse trainees whose reactions to symptoms or behaviours might range from sadness to fear of the patients..$^{(35,40)}$

Despite many staff saying that offering care was meaningful to them, some admitted that the nature of the care can

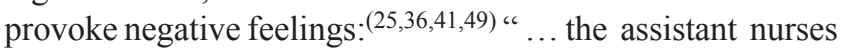
described feeling that they were only actually meeting the residents' most basic physical needs." ${ }^{(49)}$ Nursing assistants talked about how difficult they found it to "leave the job at work" (i.e., that it occupied their minds at home), while nurses in another study spoke of how death of patients in their care can provoke in them a fear of their own death. ${ }^{(26,50)}$ They described coping with this emotional impact through support from co-workers, families, the patient's families, and strategies such as humour, adjusting expectations for treatment (comfort, not cure), and sharing the work tasks. ${ }^{(24,35,43,54)}$

\section{Organizational factors}

A worker's desire to offer the best care was often seen as confounded by the system within which they work. Across care settings organizational factors impacted patient care: policies (such as individualized care plans or meal choices) appearing only on paper and not in practice; lack of infrastructure; difficulty with system navigation/coordination; poor support from management; and poor organization in the workplace. $(29,34,38,48)$ Rural physicians also described difficulties with access to resources. ${ }^{(28)}$ Staff reported that long-term care policies, such as moving later-stage patients to separate wards, caused stress to both workers and patients. ${ }^{(54)}$

The availability of resources, including time, money, and staffing, were frequently mentioned. Adequate staffing levels were linked to job satisfaction, and a failure to provide this often resulted in descriptions from staff of a lack of quality care, and a conveyor belt approach. ${ }^{(23,26,38,41,48)}$ Burnout and feelings of stress related to the work were linked to understaffing. ${ }^{(48)}$ In one case, management's lack of understanding of the specialized needs of dementia patients was related to understaffing: "Patients with dementia can often appear to be physically well. As a result, they can be seen by managers and others as not requiring total care. The nurses felt that manager's lack of understanding of the cognitive deficits associated with dementia resulted in less than adequate staffing levels."(33)

Lack of time was described as confounding the workers' desire to offer good care, and causing negative feelings, such as frustration and irritation. ${ }^{(29,41,42)}$ Money was also cited as a resource that could impact job satisfaction, not only in terms of pay but also in benefits and tuition support. ${ }^{(6)}$

\section{Relationships on the job}

Staff described the relationships they have with a variety of people they come into contact with on the job. 
A positive relationship with PwD: The relationship with the PwD was discussed in several studies, particularly the importance of having a positive relationship with patients and the impact of this on job satisfaction. ${ }^{(42,47)}$ Assistant nurses described feeling valued by the residents of their institution, and how this meant a great deal to them: "Some said that at times the elderly residents were also very grateful and that they gave them a great deal in return." ${ }^{(49)}$ This positive relationship was also discussed in terms of provision of care, ${ }^{(41)}$ and specifically of the intertwined nature of this relationship between the patient and the carer. ${ }^{(32,54)}$

The PwD's family: Staff in long-term and acute care described how having a positive relationship with the PwD's family positively impacted patient care. ${ }^{(26,27,31)}$ Long-term care staff cited the effect of this relationship on their ability to carry out their work and sometimes perceived families as frustrated, uneducated about dementia, and having inadequate support and education. ${ }^{(46)}$ Community care workers reported that families who understood dementia made fewer demands and were largely grateful for the care offered, which resulted in job satisfaction. ${ }^{(47)}$ Staff in an acute care setting said that being able to ensure that the family was happy with the care provided is important to them, ${ }^{(33)}$ but in another acute care setting this relationship was described as a complicated one- - "a double-edged sword" where the staff felt that the families sometimes viewed this as respite care, or argued with staff over care decisions. ${ }^{(28)}$ This need to balance patient and family needs was echoed by staff in a study of mixed settings (day centre, community care, longterm care) where they described how the relationship with the family may not always be positive, with disagreements about care and sometimes even accusation of misconduct, such as theft. ${ }^{(41)}$ Staff in a residential care facility talked of the gratitude many family members had for the carers' work, but also noted that many families defer to the staff and are not very involved with the patients for a variety of reasons including the emotional impact of dementia. ${ }^{(55)}$

Teamwork on the job: Positive relationships with coworkers was cited as important to job satisfaction in nonnursing frontline staff in both residential and community care. ${ }^{(23,47)}$ This was cited by both nursing and non-nursing frontline staff in residential and community care as a factor for good care and specifically in being able to appropriately manage aggressive behaviours. ${ }^{(25,33,49)}$ In one case, registered nurses and licensed practical nurses indicated that they preferred more involvement with team members such as physicians and allied health professionals, as they felt that better involvement among all team members would lead to greater knowledge. ${ }^{(31)}$

Dealing with Management: A positive relationship with management/administration was an important component for job satisfaction of some workers. Long-term care workers (nurses, nurse trainees, and non-nursing frontline) described positive organizational support and relationships with their management as necessary to providing best care. Without these, they became frustrated and resigned to routine work. ${ }^{(25)}$ When leadership was perceived as unskilled or uninterested in dementia care it lowered staff morale ${ }^{(31)}$ and undermined the desire to provide good care: “... residential care nurses expressed concern about lack of resources, lack of time and poor management support. This in turn adversely affected nursing care available for residents, creating feelings of both frustration, anger and sometimes apathy as they did not have the power to change the situation."(41)

In both long-term care and community care, autonomy and the power to make decisions were cited by staff as important to job satisfaction, ${ }^{(23,47)}$ with good communication with upper staff and shared aims of care being cited as major factors in taking and staying with community care work. ${ }^{(47)}$

\section{Theme Interactions}

The themes described above impacted each other to varying degrees (Figure 3).

We can see that education and organizational factors are two areas more likely to impact the others rather than to be impacted, while the emotional impact of the job is affected by all the other theme areas. Education and organizational factors affect both job satisfaction and patient care in a variety of ways, and it seems obvious that it would be difficult, for example, for workers to feel more positive about the jobs they do without first tackling issues in these two areas. The evidence presented here shows that many paid dementia care workers from a spectrum of backgrounds receive little to no dementia-specific education or training and identify this as a key issue. Additionally, there was evident frustration with organizational factors that do not take into consideration the extra care and resources required by dementia patients. Participants from the studies were often keenly aware that they were not able to offer the best care they might be capable

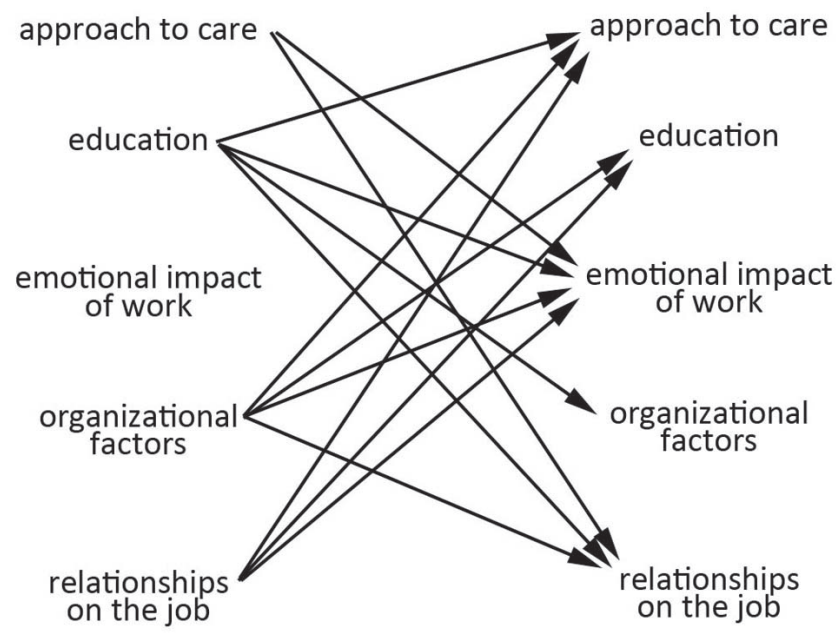

FIGURE 3. Direction of impact between themes, left to right 
of providing, either due to lack of understanding of their patients' needs and behaviours, or due to organizational issues that were out of their control.

\section{DISCUSSION \& CONCLUSION}

\section{Principal Findings}

Much work has been done to study the perspectives of paid dementia care workers using qualitative methods but, to date, there has been no attempt to synthesize this collectively. Our exploration of this uncovered five overarching themes of education/training, organizational factors, emotional impact of the work, approach to care, and relationships on the job, and showed how themes interacted with each other.

\section{Strength and Limitations}

The systematic search, collection, review and synthesis of the findings from a wide range of work, as well as the inclusion of Knowledge Users from our target groups, strengthens our confidence that we have represented the cumulative insights of paid dementia care workers. Our interest in the voices of all paid dementia care workers means that we did not limit ourselves to a synthesis that considered only one stetting or type of participant. Because many of the studies included multiple types of participants and multiple settings, the ability to tease out which perspectives may have been more or less associated with a given group or setting was not a realistic goal of this work; however, the inclusion of perspectives from the spectrum of paid care, from community care to long-term residential care, allows us to present a more complete picture of the current situation. The mix of care providers included would seem to be a reasonable reflection of the paid-care situation in Canada, which strengthens the applicability of this review to real-world settings.

That we have synthesized studies where different methods or theoretical approaches may have been used should also be noted. However, our desire was to paint a broad picture of the existing research, with an eye to future work of a narrower focus; thus, we felt this approach justified.

The quality review of the papers included in this synthesis also highlighted issues of note. That only $50 \%$ of the studies included had stated methodology means that there is little transparency in the choice of methodology and defense of this. That most papers described their collection and analysis systemically, but not necessarily transparently, is likely less indicative of poor methods than of poor reporting. Adding even a small amount of information to these sections could ensure better transparency.

\section{Implications}

This synthesis was carried out with the intention that it would be a springboard to more focused areas of research and collaborations with Knowledge Users. We expect these results will also be of interest and use to all those working in the field of dementia care, especially those engaged in research around improving patient care and care systems, and dementia-care educators.

It is clear that organizations wishing to improve dementia care need to invest in education and training - but characteristics of education and training that work best are not well established. While patient-centred approaches can give rise to satisfaction, they can also cause distress without the ability to provide such care. Paid carers are often engaged in the later stages of the illness, when the PwD's needs are more complex, yet this review clearly indicates that many of the workers performing this complex care feel ill equipped educationally to provide this. Focusing educational efforts at residential care staff would appear to be one way to address this. Additionally, the educational needs of care leaders must be considered, as closing the gap between policy and practice appears to work best when everyone knows what to do.

Initial feedback from our Knowledge Users has indicated a high level of interest in the areas of education and organizational factors. To ensure that we carry forward with research that is responsive to their needs and questions, we are working in planned sessions with Knowledge Users to discuss research and work partnerships in areas that have emerged from this synthesis, and how best to transfer for the results of this synthesis into their environments.

\section{ACKNOWLEDGEMENTS}

We would like to gratefully acknowledge the Canadian Institutes for Health Research for funding this project with a Knowledge Synthesis Grant (KRS-102065), as well as all of the Knowledge Users who gave their time and expertise, and our research assistant, Ms. Veronica Simmonds, for her excellent contributions to this synthesis.

\section{CONFLICT OF INTEREST DISCLOSURES}

The authors declare that no conflicts of interest exist.

\section{REFERENCES}

1. Canadian Study of Health and Aging Working Group. Canadian Study of Health and Aging: study methods and prevalence of dementia. Can Med Assoc J. 1994;150(6):899-913.

2. Hebert R, Dubois MF, Wolfson C, et al. Factors associated with long-term institutionalization of older people with dementia: data from the Canadian Study of Health and Aging. J Gerontol A Biol Sci Med Sci. 2001;56(11):M693-M699.

3. Zimmerman S, Sloane PD, Williams CS, et al. Dementia care and quality of life in assisted living and nursing homes. Gerontologist. 2005;45 (Suppl 1):133-46. 
4. Zimmerman S, Williams CS, Reed PS, et al. Attitudes, stress, and satisfaction of staff who care for residents with dementia. Gerontologist. 2005;45(Suppl 1):96-105.

5. Brodaty H, Draper B, Low LF. Nursing home staff attitudes towards residents with dementia: strain and satisfaction with work. J Adv Nurs. 2003;44(5):583-90.

6. Sung HC, Chang SM, Tsai CS. Working in long-term care settings for older people with dementia: nurses' aides. J Clin Nurs. 2005;14(5):587-93.

7. Train G, Nurock S, Kitchen G, et al. A qualitative study of the views of residents with dementia, their relatives and staff about work practice in long-term care settings. Int Psychogeriatr. 2005;17(2):237-51.

8. Page S, Keady J. Sharing stories: a meta-ethnographic analysis of 12 autobiographies written by people with dementia between 1989 and 2007. Ageing and Society. 2010;30(3):511-26.

9. Al-Janabi H, Coast J, Flynn T. What do people value when they provide unpaid care for an older person? A meta-ethnography with interview follow-up. Soc Sci Med. 2008;67(1):111-21.

10. Department of Health. Living Well with Dementia: a National Dementia Strategy. London, UK: Department of Health; 2009.

11. Noblit GW, Hare RD. Meta-Ethnography: Synthesizing Qualitative Studies. Newbury Park, CA: Sage Publications; 1988.

12. Munro SA, Lewin SA, Smith HJ, et al. Patient adherence to tuberculosis treatment: a systematic review of qualitative research. PLoS Med. 2007;4:e238.

13. Tong A, Lowe A, Sainsbury P, et al. Experiences of parents who have children with chronic kidney disease: a systematic review of qualitative studies. Pediatrics. 2008;121(2):349-60.

14. Garside R, Britten N, Stein K. The experience of heavy menstrual bleeding: a systematic review and meta-ethnography of qualitative studies. $J$ Adv Nurs. 2008;63(6):550-62.

15. Malpass A, Shaw A, Sharp D, et al. "Medication career" or "moral career"? The two sides of managing antidepressants: a meta-ethnography of patients' experience of antidepressants. Soc Sci Med. 2009;68(1):154-68.

16. Schumm K, Skea Z, McKee L, et al. 'They're doing surgery on two people': a meta-ethnography of the influences on couples' treatment decision making for prostate cancer. Health Expect. 2010;13(4):335-49.

17. Bridges J, Flatley M, Meyer J. Older people's and relatives' experiences in acute care settings: systematic review and synthesis of qualitative studies. Int J Nurs Stud. 2010;47(1):89-107.

18. Graham ID, Logan J, Harrison MB, et al. Lost in knowledge translation: time for a map? J Contin Educ Health Prof. 2006;26(1):13-24

19. Spencer L, Ritchie J, Lewis J, et al. National Research Centre for Social Research, Quality in Qualitative Evaluation: a framework for assessing research evidence. London, UK: Strategy Unit, Cabinet Office; 2003.

20. Mays N, Pope C. Assessing quality in qualitative research. $B M J$. 2000;320(7226):50-52.
21. Muhr T. Atlas.ti Scientific Software Develeopment GmbH. 2004. Available from: http://www.atlasti.com/copyright.html

22. Pope C, Mays N, Popay J. Synthesizing Qualitative and Quantitative Health Evidence: A Guide to Methods [electronic resource]. Maindenhead, UK: Open University Press, McGraw Hill Education; 2007. Available from http://onlinelibrary.wiley. com/doi/10.1111/j.1467-9566.2007.1077_5.x/abstract

23. Karner TX, Montgomery RJ, Dobbs D, et al. Increasing staff satisfaction. The impact of SCUs and family involvement. $J$ Gerontol Nurs. 1998;24(2):39-44.

24. Hellner BM, Norberg A. Intuition: two caregivers' descriptions of how they provide severely demented patients with loving care. Int J Aging Hum Dev. 1994;38(4):327-38.

25. Skovdahl K, Kihlgren AL, Kihlgren M. Different attitudes when handling aggressive behaviour in dementia-narratives from two caregiver groups. Aging Ment Health. 2003;7(4):277-86.

26. McCarty E, Drebing C. Burden and professional caregivers: tracking the impact. J Nurses Staff Dev. 2002;18(5):257-57.

27. Nolan L. Caring for people with dementia in the acute setting: a study of nurses' views. Br J Nurs. 2007;16(7):419-22.

28. Borbasi S, Jones J, Lockwood C, et al. Health professionals' perspectives of providing care to people with dementia in the acute setting: Toward better practice. Geriatr Nurs. 2006;27(5):300-08.

29. Cowdell F. Care of older people with dementia in an acute hospital setting. Nurs Stand. 2010;24(23):42-48.

30. Andrews M. Dementia Care in Remote Communities: perceptions of registered nurses [PhD thesis]. Saskatoon, SK: University of Saskatchewan; 2008.

31. Albinsson L, Strang P. Staff opinions about the leadership and organisation of municipal dementia care. Health Soc Care Community. 2002;10(5):313-22.

32. Holst G, Edberg A, Hallberg I. Nurses' narrations and reflections about caring for patients with severe dementia as revealed in systematic clinical supervision sessions. J Aging Stud. 1999;13(1):89-107.

33. Earle V. Nurses' Experiences Caring for Patients with Dementia: a phenomenological study [Masters thesis]. St. John's, NL: Memorial University of Newfoundland; 2003.

34. Miller M. Nursing Staff Responses to Physically Aggressive Behaviour in Cognitively Impaired Institutionalized Elderly: a qualitative study [PhD thesis]. Coral Gables, FL: University of Miami; 1996.

35. Roper JM, Shapira J, Beck A. Nurse caregiver feelings about agitation in Alzheimer's disease. J Gerontol Nurs. 2001;27(12):32-39.

36. Adams WL, McIlvain HE, Geske JA, et al. Physicians' perspectives on caring for cognitively impaired elders. Gerontologist. 2005;45(2):231-39.

37. Sandvide A, Astrom S, Norberg A, et al. Violence in institutional care for elderly people from the perspective of involved care providers. Scand J Caring Sci. 2004;18(4):351-57.

38. Jansen L, Forbes DA, Markle-Reid M, et al. Formal care providers' perceptions of home- and community-based services: 
informing dementia care quality. Home Health Care Serv $Q$. 2009;28(1):1-23.

39. Ayalon L. Beliefs and practices regarding Alzheimer's disease and related dementias among Filipino home care workers in Israel. Aging Ment Health. 2009;13(3):456-62.

40. Robinson A, Cubit K. Caring for older people with dementia in residential care: nursing students' experiences. $J$ Adv Nurs. 2007;59(3):255-63.

41. Edberg AK, Edfors E. Nursing care for people with frontallobe dementia - difficulties and possibilities. Int Psychogeriatr. 2008;20(2):361-74.

42. Olsson A, Hallberg IR. Caring for demented people in their homes or in sheltered accommodation as reflected on by home-care staff during clinical supervision sessions. $J A d v$ Nurs. 1998;27(2):241-52.

43. Humphrey J. Nurses' Experience of Caring for Dementia Patients Who Exhibit Challnging Behaviours [MSc thesis]. Buffalo, NY: D'Youville College; 2009.

44. MacDonald C. Care assistants' views and experience of challenging behaviour in dementia. J Dement Care. 2007;15(4):33-38.

45. Chang E, Daly J, Johnson A, et al. Challenges for professional care of advanced dementia. Int J Nurs Pract. 2009;15(1):41-47.

46. Pashby P, Hann J, Sunico ME. Dementia care planning: shared experience and collaboration. J Gerontol Soc Work. 2009;52(8):837-48.

47. Ryan T, Nolan M, Enderby P, et al. 'Part of the family': sources of job satisfaction amongst a group of communitybased dementia care workers. Health Soc Care Community. 2004;12(2):111-18.
48. Kuremyr D, Kihlgren M, Norberg A, et al. Emotional experiences, empathy and burnout among staff caring for demented patients at a collective living unit and a nursing home. $J$ Adv Nurs. 1994;19(4):670-79.

49. Kristiansen L, Hellzen O, Asplund K. Swedish assistant nurses' experiences of job satisfaction when caring for persons suffering from dementia and behavioural disturbances. An interview study. Int J Qual Stud Health Well-being. 2006;1(4):245-56.

50. Norberg A, Asplund K. Caregivers' experience of caring for severely demented patients. West J Nurs Res. 1990;12(1):75-84.

51. Eriksson C, Saveman BI. Nurses' experiences of abusive/nonabusive caring for demented patients in acute care settings. Scand J Caring Sci. 2002;16(1):79-85.

52. Akerlund B. Dementia Care in an Ethical Perspective: an exploratory study of caregivers' experiences of ethical conflicts when feeding severely demented patients [PhD thesis]. Umea, Sweden: Umea University; 1990.

53. Hasselkus BR. Everyday ethics in dementia day care: narratives of crossing the line. Gerontologist. 1997;37(5):640-49.

54. Berg A, Hallberg IR, Norberg A. Nurses' reflections about dementia care, the patients, the care and themselves in their daily caregiving. Int J Nurs Stud. 1998;35(5):271-82.

55. Setterlund D. Dementia care staff and family carers: their relationship in the context of care. Australasian Journal on Ageing. 1998;17(3):135-39.

Correspondence to: Kenneth Rockwood, MD, FRCPC, FRCP, Centre for Health Care of the Elderly, 1421-5955 Veterans' Memorial Lane, Halifax, NS B3H 2E1, Canada

E-mail: Kenneth.Rockwood@dal.ca 


\section{APPENDIX A: SEARCH TERMS}

\section{Final Refined Search}

(Nurse OR Nursing OR Worker OR "Health Personnel" OR "Healthcare Personnel" OR "Health Care Personnel" OR Homecare OR "Home Care" OR Staff OR Practitioner OR Therapist OR Physician OR Doctor OR Caregiver OR "Care Giver" OR "Care Provider" OR "Care Assistant" OR Administrator OR Aide OR Clergy OR Auxiliary OR Housekeeping OR "Nutrition Services" OR "Shift Supervisor" OR Sitter OR "Support Service People" OR "Team Leader" OR Dietitian OR Doctor OR Nutritionist OR Physician OR Assistant OR Psychiatrist OR "Health Care Professional" OR "Healthcare Professional" OR "Health Professional") AND (Dementia OR Alzheimer)

AND (qualitative OR "mixed method" OR ethnography OR Phenomenology OR "Grounded Theory") 
APPENDIX B - CHARACTERISTICS OF PAPERS INCLUDED.

\begin{tabular}{|c|c|c|c|c|c|c|c|c|c|c|c|c|c|c|c|c|c|c|c|c|c|c|c|c|}
\hline \multirow[t]{2}{*}{ Author } & \multirow[t]{2}{*}{ Country } & \multirow[t]{2}{*}{ Year } & \multicolumn{7}{|c|}{ Participant type } & \multicolumn{9}{|c|}{ Setting } & \multicolumn{6}{|c|}{ Stated methodology } \\
\hline & & & 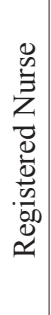 & 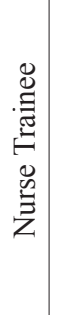 & 面 & 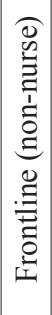 & 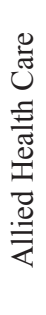 & 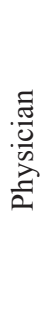 & 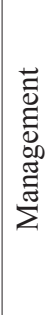 & 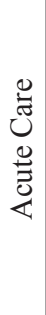 & 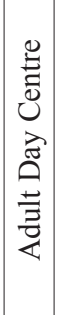 & 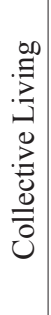 & 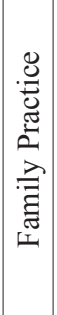 & 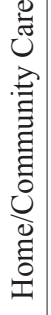 & 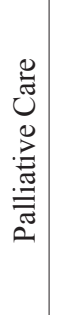 & 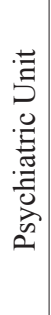 & 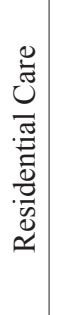 & : & 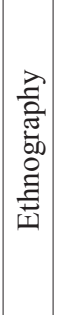 & 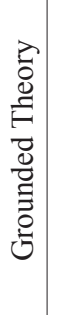 & 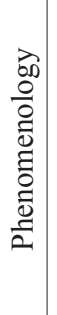 & 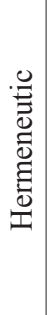 & 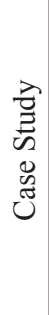 & 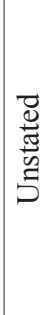 \\
\hline Adams,W. L.et al & USA & 2005 & & & & & $\mathrm{x}$ & $\mathrm{x}$ & & & & & $\mathrm{x}$ & & & & & & & & & & & $\mathrm{x}$ \\
\hline Akerlund,B.M. & Sweden & 1990 & $\mathrm{x}$ & & $\mathrm{x}$ & $\mathrm{x}$ & & & & & & & & & & $\mathrm{x}$ & & & & & $\mathrm{x}$ & $\mathrm{x}$ & & \\
\hline Albinsson,L.;Strang,P. & Sweden & 2002 & $\mathrm{x}$ & & $\mathrm{x}$ & & & & & & & & & & & & $\mathrm{x}$ & & & & $\mathrm{x}$ & & & \\
\hline Andrews,M. & Canada & 2008 & $\mathrm{x}$ & & & & & & & $\mathrm{x}$ & & & & & & & & & & $\mathrm{x}$ & & & & \\
\hline Ayalon,L. & Israel & 2009 & & & & $\mathrm{x}$ & & & & & & & & $\mathrm{x}$ & & & & & & & & & & $\mathrm{x}$ \\
\hline Berg,A.et al & Sweden & 1998 & $\mathrm{x}$ & & & & & & & & & & & & & & $\mathrm{x}$ & & & & $\mathrm{x}$ & & & \\
\hline Borbasi,S.et al & Australia & 2006 & & & & & $\mathrm{x}$ & $\mathrm{x}$ & & $\mathrm{x}$ & & & & & & & & & & & & & & $\mathrm{x}$ \\
\hline Chang,E. et al. & Australia & 2009 & $\mathrm{x}$ & & & $\mathrm{x}$ & $\mathrm{x}$ & $\mathrm{x}$ & & $\mathrm{x}$ & & & & $\mathrm{x}$ & $\mathrm{x}$ & & $\mathrm{x}$ & $\mathrm{x}$ & & & & & & \\
\hline Coldwell & UK & 2010 & $\mathrm{x}$ & & & $\mathrm{x}$ & & & & $\mathrm{x}$ & & & & & & & & & $\mathrm{x}$ & & & & & \\
\hline Earle,Vicki C. & Canada & 2003 & $\mathrm{x}$ & & & & & $\mathrm{x}$ & & & & & & & & & $\mathrm{x}$ & & & & $\mathrm{x}$ & & & \\
\hline Edberg,Aet al & $\begin{array}{c}\text { Australia, } \\
\text { Sweden, UK }\end{array}$ & 2008 & $\mathrm{x}$ & & & $\mathrm{x}$ & $\mathrm{x}$ & & & & $\mathrm{x}$ & & & $\mathrm{x}$ & & & $\mathrm{x}$ & & & & & & & $\mathrm{x}$ \\
\hline Eriksson,C.;Saveman,B. & Sweden & 2002 & $\mathrm{x}$ & & & & & & & $\mathrm{x}$ & & & & & & & & & & & & & & $\mathrm{x}$ \\
\hline Hasselkus,B. R. & USA & 1997 & $\mathrm{x}$ & & & $\mathrm{x}$ & $\mathrm{x}$ & & $\mathrm{x}$ & & $\mathrm{x}$ & & & & & & & & & & $\mathrm{x}$ & & & \\
\hline Hellner,BM.Norberg,A. & Sweden & 1994 & & & & $\mathrm{x}$ & & & & & & & & & & & $\mathrm{x}$ & & & & $\mathrm{x}$ & & & \\
\hline Holst,GÃ;et al & Sweden & 1999 & $\mathrm{x}$ & & & & & & & & & & & & & $\mathrm{x}$ & & & & & $\mathrm{x}$ & $\mathrm{x}$ & & \\
\hline Humphrey, J. & Canada & 2009 & $\mathrm{x}$ & & & & & & & $\mathrm{x}$ & & & & & & & & & & & $\mathrm{x}$ & $\mathrm{x}$ & & \\
\hline Jansen,L. et al & Canada & 2009 & $\mathrm{x}$ & & & $\mathrm{x}$ & $\mathrm{x}$ & & & & & & & $\mathrm{x}$ & & & & & & & & & & $\mathrm{x}$ \\
\hline Karner,T. X.. Et al & USA & 1998 & & & & $\mathrm{x}$ & & & & & & & & & & & $\mathrm{x}$ & & & $\mathrm{x}$ & & & & \\
\hline Kristiansen, L. & Sweden & 2006 & $\mathrm{x}$ & & & $\mathrm{x}$ & & & & & & $\mathrm{x}$ & & & & & & & & & & & & $\mathrm{x}$ \\
\hline Kuremyr,D et al & Sweden & 1994 & $\mathrm{x}$ & $\mathrm{x}$ & & $\mathrm{x}$ & & & & & & $\mathrm{x}$ & & & & & $\mathrm{x}$ & & & & & & & $\mathrm{x}$ \\
\hline MacDonald,C. & UK & 2007 & & & & $\mathrm{x}$ & & & & & & & & & & & $\mathrm{x}$ & & & & & & & $\mathrm{x}$ \\
\hline McCarty,E. F.;Drebing,C. & Canada & 2003 & $\mathrm{x}$ & & & $\mathrm{x}$ & $\mathrm{x}$ & $\mathrm{x}$ & & & & & & & & & $\mathrm{x}$ & & & & & & & $\mathrm{x}$ \\
\hline Miller,M.F. & USA & 1996 & $\mathrm{x}$ & & $\mathrm{x}$ & $\mathrm{x}$ & & & & & & & & & & & $\mathrm{x}$ & & & & & & & $\mathrm{x}$ \\
\hline Nolan,L. & USA & 2006 & $\mathrm{x}$ & & & & & & & $\mathrm{x}$ & & & & & & & & & & & & $\mathrm{x}$ & & \\
\hline Norberg,A.;Asplund,K. & Sweden & 1990 & $\mathrm{x}$ & & $\mathrm{x}$ & $\mathrm{x}$ & & & & & & & & & & & $\mathrm{x}$ & & & & $\mathrm{x}$ & & & \\
\hline Olsson,A.Hallberg,I. R. & Sweden & 1998 & $\mathrm{x}$ & & $\mathrm{x}$ & $\mathrm{x}$ & & & $\mathrm{x}$ & & & & & $\mathrm{x}$ & & & & & $\mathrm{u}$ & & & $\mathrm{x}$ & & \\
\hline Pashby,P al & Canada & 2009 & $\mathrm{x}$ & & $\mathrm{x}$ & $\mathrm{x}$ & $\mathrm{x}$ & $\mathrm{x}$ & & & & & & & & & $\mathrm{x}$ & & & & & & & $\mathrm{x}$ \\
\hline Robinson,A.;Cubit,K. & Australia & 2007 & $\mathrm{x}$ & $\mathrm{x}$ & & & & & & & & & & & & & $\mathrm{x}$ & & & & & & & $\mathrm{x}$ \\
\hline Roper,J. et al & UK & 2001 & $\mathrm{x}$ & & & & & & & & & & & & & $\mathrm{x}$ & & & $\mathrm{x}$ & & & & & \\
\hline Ryan,T.et al & UK & 2004 & & & & $\mathrm{x}$ & & & & & & & & $\mathrm{x}$ & & & & & & & & & & $\mathrm{x}$ \\
\hline Sandvide,A. et al & Sweden & 2004 & $\mathrm{x}$ & & $\mathrm{x}$ & $\mathrm{x}$ & & & & & & $\mathrm{x}$ & & & & & $\mathrm{x}$ & & & & & & & $\mathrm{x}$ \\
\hline Setterlund, DS. & Australia & 1998 & & & & $\mathrm{x}$ & & & & & & & & & & & $\mathrm{x}$ & & & & & & & $\mathrm{x}$ \\
\hline Skovdahl,K.et al & Sweden & 2003 & $\mathrm{x}$ & $\mathrm{x}$ & & $\mathrm{x}$ & & & & & & & & & & & $\mathrm{x}$ & & & & $\mathrm{x}$ & & & \\
\hline Sung,H. C.et al & Taiwan & 2005 & & & & $\mathrm{x}$ & & & & & & & & & & & $\mathrm{x}$ & & & & & & & $\mathrm{x}$ \\
\hline
\end{tabular}

